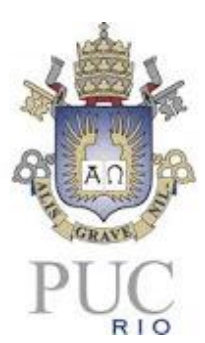

PONTIFÍCIA UNIVERSIDADE CATÓLICA DO RIO DE JANEIRO

A implementação de procedimentos operacionais padrões em uma empresa de limpeza

Sergio Tostes Newlands Freire

TRABALHO DE CONCLUSÃO DE CURSO

CENTRO DE CIÊNCIAS SOCIAIS - CCS DEPARTAMENTO DE ADMINISTRAÇÃO

GRADUAÇÃO EM ADMINISTRAÇÃO DE EMPRESAS 


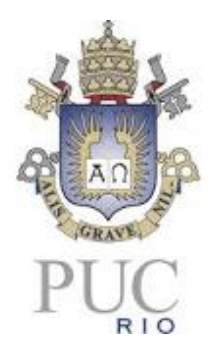

Sérgio Tostes Newlands Freire

\section{A implementação de procedimentos operacionais padrões em uma empresa de limpeza}

\section{Trabalho de Conclusão de Curso}

Trabalho de Conclusão de Curso, apresentado ao programa de graduação em Administração de Empresas da PUC-Rio como requisito parcial para obtenção do título de graduação em Administração

Orientadora: Claudia Soares 
"If you can't fly, run. If" you can't run, walk If you can't walk, crawl. But whatever you do, You have to keep moving forward"

(Martin Luther King Jr.) 


\section{Agradecimentos}

Gostaria de agradecer principalmente à minha família. Por estar do meu lado sempre que precisei e mesmo quando achava que não os necessitava. Por todo o apoio incondicional que meus pais me deram e continuam dando em minha vida profissional e pessoal. Ao meu pai e melhor amigo, Sergio Freire, por ser um exemplo de caráter e profissionalismo. À minha mãe, que todo dia me mostra o quão boa e carinhosa uma pessoa pode ser. Aos meus irmãos, que apesar das brigas sempre me apoiaram em minhas decisões e me incentivaram a seguir meu caminho fosse ele qual for.

Obrigado aos meus amigos pela paciência, amizade e cumplicidade que sempre tiveram perante mim mesmo nos momentos mais difíceis em minha vida. Em especial obrigado ao meu amigo Fabio Moura, que eu tenho certeza que, apesar de não estar mais presente comigo fisicamente, me protege dos céus e hoje virou meu anjo da guarda.

Tenho que agradecer também a minha orientadora Claudia Soares, que apesar da minha falta de organização e ocasionalmente perda de prazos combinados sempre acreditou em mim e me ajudou a completar esta etapa que, sem dúvida, será uma das mais importantes e marcantes da minha vida.

Obrigado também a todos os meus professores do curso de Administração, que me prepararam para enfrentar quaisquer desafios que possam surgir na minha vida profissional, e através de suas aulas e dinâmicas me fizeram crescer como profissional e ser humano.

E não poderia de deixar de agradecer a Deus, que me guarda e me conforta nas horas difíceis e me dá a força que preciso para continuar seguindo em frente em todos os momentos da minha vida. 


\title{
Resumo:
}

Freire, Sergio. Soares, Cláudia. A implementação de procedimentos operacionais padrões em uma empresa de limpeza. Rio de Janeiro, 2017. Trabalho de Conclusão de Curso - Departamento de Administração. Pontifícia Universidade Católica do Rio de Janeiro

A Blim, empresa de limpeza analisada no presente estudo foi criada em 2015 com um único serviço dentro de seu portfólio e, ao longo de quase três anos de vida expandiu seus serviços e cresceu de forma acelerada, com que fizesse que sua gestão por processo fosse comprometida e consequentemente o controle operacional.

O presente trabalho teve como objetivo analisar o processo de venda da microempresa fim de detectar quais pontos críticos do processo e quais melhorias e procedimentos operacionais padrões poderiam ser implementados afim de melhorar o processo.

Palavras-chave:

Serviço, Gestão por Processo, Procedimento operacional padrão.

\begin{abstract}
Freire, Sergio. Soares, Cláudia. The implementation of standard operating procedures in a cleaning company. Rio de Janeiro, 2017. Term Paper - Business Administration Department. Pontifical Catholic University of Rio de Janeiro.
\end{abstract}

Blim, a cleaning company analyzed in the present study, was created in 2015 with a single service within its portfolio and, over almost three years of life, expanded its services and grew in an accelerated way, so that its business process management was compromised and consequently the operational control.

The objective of this study was to analyze the sales process of the microenterprise in order to detect which are critical points of the process and what improvements and standard operating procedures could be implemented in order to improve the process

Key Words:

Service, business process management, standard operating procedures 
Sumário

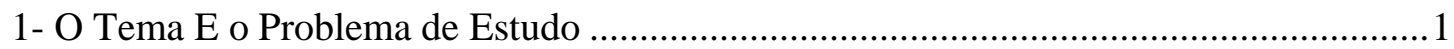

1.1 - Introdução ao Tema e ao Problema do Estudo........................................................ 1

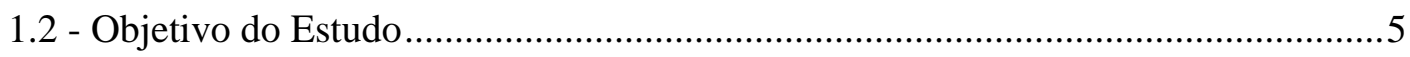

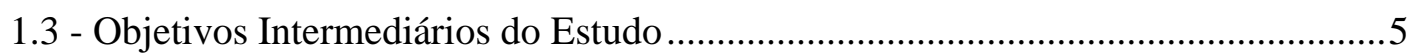

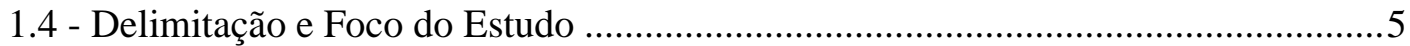

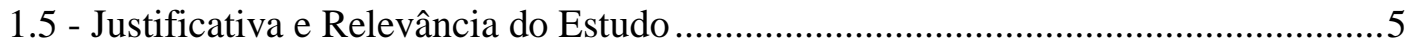

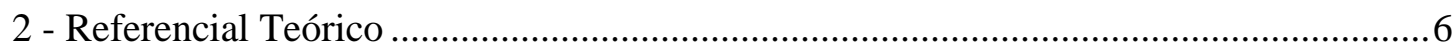

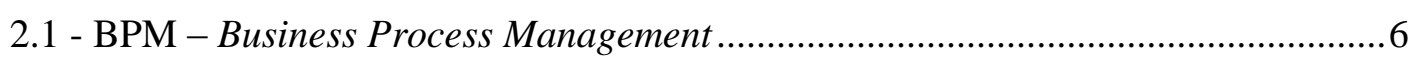

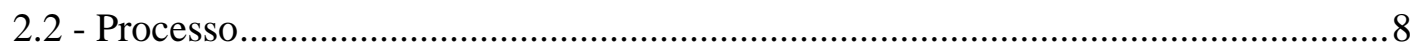

2.3 - Procedimento Organizacional Padrão (POP's) ……………………….................... 9

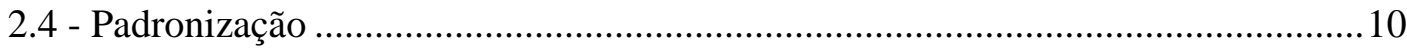

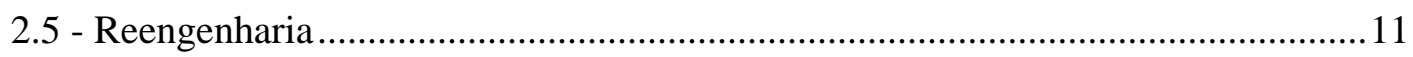

3. Método Escolhido para a Coleta e Processamento de Dados ........................................13

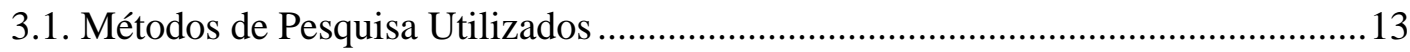

3.2 Procedimentos e Instrumentos de Coleta de Dados.................................................13

3.3 Formas de Tratamento e Análise de Dados ............................................................15

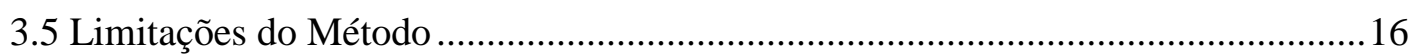

4 Apresentação e Análise dos Resultados............................................................................ 17

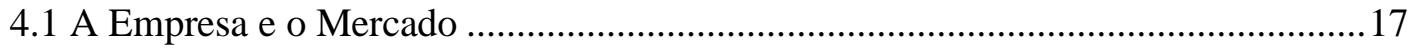

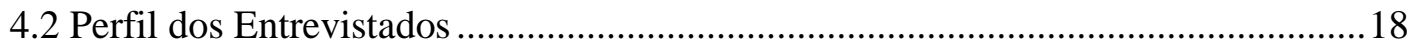

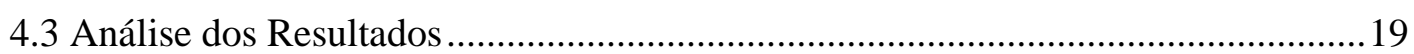

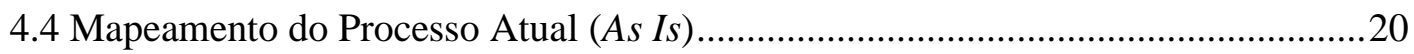

4.4.1 - Etapa 1: Colheita de Informações e Agendamento da Visita .........................21

4.4.2 - Etapa 2: Realização da Visita Técnica .......................................................2 21

4.4.3 - Etapa 3: Levantamento de custos e envio do orçamento:...............................22

4.4.4 - Etapa 4: Formalização de Contrato e Documentações: ..................................22

4.4.5 - Etapa 5: Planejamento e Mobilização do Operacional:...................................22

4.4.6 - Etapa 6: Prestação do Serviço: .......................................................................23

4.4.7 - Etapa 7: Pós-venda e Feedback .................................................................2 23

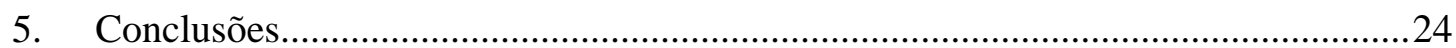

5.1 Pontos Críticos do Processo de Venda ……............................................................24

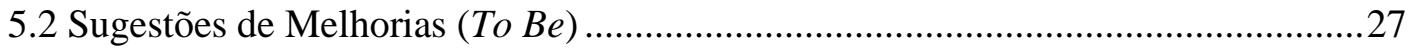

5.3 Sugestões e Recomendações para Novos Estudos................................................. 32

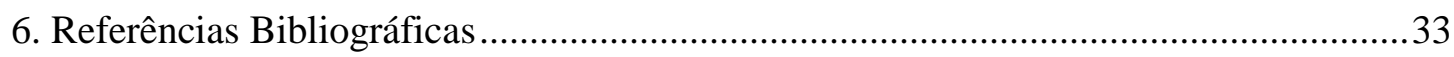

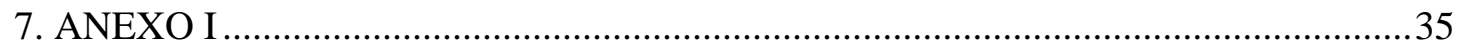

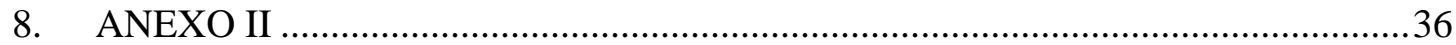




\section{1- O Tema E o Problema de Estudo}

\section{1 - Introdução ao Tema e ao Problema do Estudo}

O cumprimento das tarefas da melhor maneira possível é uma preocupação geral de toda a população mundial, não importando renda, localização ou cultura. Independentemente se isto é um trajeto na escolha de um motorista fazer entregas, uma dona de casa fazer compras ou uma empresa prestar serviços. Em todos os casos citados, o operador da tarefa visa executá-la da melhor forma possível e evitar qualquer tipo de desperdício, seja ele tempo, dinheiro ou energia. Pode-se imaginar assim que todos os indivíduos e organizações procuram estabelecer métodos de trabalho para o aperfeiçoamento da realização de suas atividades de maneira a torná-las as menos dispendiosas possíveis sem prejudicar o cumprimento de seus objetivos.

Para o motorista, por exemplo, a escolha de uma ordem errada de entregas pode acarretar em um custo de combustível e uma perda de tempo muito superior a planejada. Para organizações, os prejuízos podem ser muito maiores. Sendo assim é razoável pensar que as empresas devem estar sempre tentando melhorar sua gestão de tarefas afim de otimizar seus recursos e resultados.

Segundo Muller (2003), as organizações são um conjunto de processos integrados que juntos são direcionados para a obtenção de um resultado proposto. Sendo estes processos atividades realizadas em uma sequência definida com o objetivo de produzir um serviço que tenha valor para o cliente final. O controle dessas atividades faz parte da gestão administrativa da companhia, que deve ser feita por seus controladores e gerentes, sempre alinhadas com os objetivos táticos e estratégicos da empresa.

No início da década de 90, uma nova abordagem administrativa foi proposta, a Gestão por Processos de Negócios, vindo do inglês, BPM (Business Process Management). Esta nova metodologia baseia-se na unificação da gestão de negócios com a tecnologia da informação, afim de otimizar resultados através da melhor integração de todos os processos da organização. "O BPM permite o modelamento de 
um processo já existente, o teste de inúmeras variações e o gerenciamento das inovações de uma forma rápida, fazendo com que os resultados sejam analisados com rapidez e eficiência" (SMITH; FINGAR - BPM The Third Wave 2003 p. 63).

O BPM não abrange apenas a modelagem dos processos de uma organização, mas também a implementação de novos procedimentos e o controle de toda a unidade de negócio afim de garantir que os processos permaneçam sempre em conformidade com os objetivos da empresa, assegurando um resultado positivo para a companhia e a satisfação dos clientes e todos os envolvidos.

Segundo Michael Rosemann (2005), acadêmico da Universidade de Tecnologia de Queensland, diante do desafio de aumentar a transparência e estruturação dos processos internos de uma organização diversos desafios são enfrentados, tais como: falta de padronização, resistência à mudança, desalinhamento da área operacional com a estratégia proposta, falta de comprometimento, desorganização, entre outros. Neste cenário o BPM surge como uma alternativa para a orientação dos envolvidos quanto a necessidade de melhoria dos processos internos para um resultado melhor.

Com a aplicação da gestão de processos nas organizações todas as tarefas devem ser reformuladas, das mais simples às mais complexas. As ferramentas do BPM monitoram a evolução dos processos de forma rápida e efetiva, com baixo custo e fácil entendimento.

Na opinião de Aalst et al (2003), a gestão de processos combina todos os procedimentos operacionais internos da organização com técnicas e softwares de gestão que, além de desenhar e executar as tarefas, também controlam e analisam todas estas atividades-chave.

Segundo Hammer (2010), o gerenciamento de processos permite que a organização crie processos de forma mais rápida, com custos mais baixos, maior precisão e flexibilidade. Para Paim (2009), o BPM elimina barreiras dentro das empresas possibilitando uma visão holística, garantindo uma maior inter-relação entre fornecedores, executores do processo e clientes.

Embora este seja um método muito difundido no exterior, no Brasil ele ainda é muito pouco explorado, apesar de estar crescendo. Segundo a pesquisa "A Evolução do BPM nas Organizações Brasileiras“ realizada pelo ELO Group (ELO GROUP, 2015), “O BPM é uma abordagem de gestão capaz de transformar as organizações a partir da orientação por processos, buscando com isso entregar melhores produtos e serviços aos seus clientes“. Ainda segundo a pesquisa, existem dois grandes grupos que adotam o 
BPM. O primeiro é formado por empresas que se transformam e posteriormente utilizam-se do gerenciamento por processos para gerir e padronizar estas transformações. E o segundo por organizações que utilizam a orientação por processos para modificar seus procedimentos internos afim de obter uma melhora em seus produtos e serviços ofertados.

Apesar da pesquisa valorizar mais o segundo grupo foi inferido que a grande maioria das empresas nacionais pertencem ao primeiro, adotando processos apenas como ferramenta de padronização de transformações já ocorridas.

Percebe-se também que, apesar da maioria das empresas terem obtido resultados positivos com a prática do BMP, os resultados relevantes ou estratégicos ficaram muito abaixo do esperado e tiveram um crescimento ano após ano muito pequeno, conforme demonstrado na Figura1: Resultados obtidos com BPM.

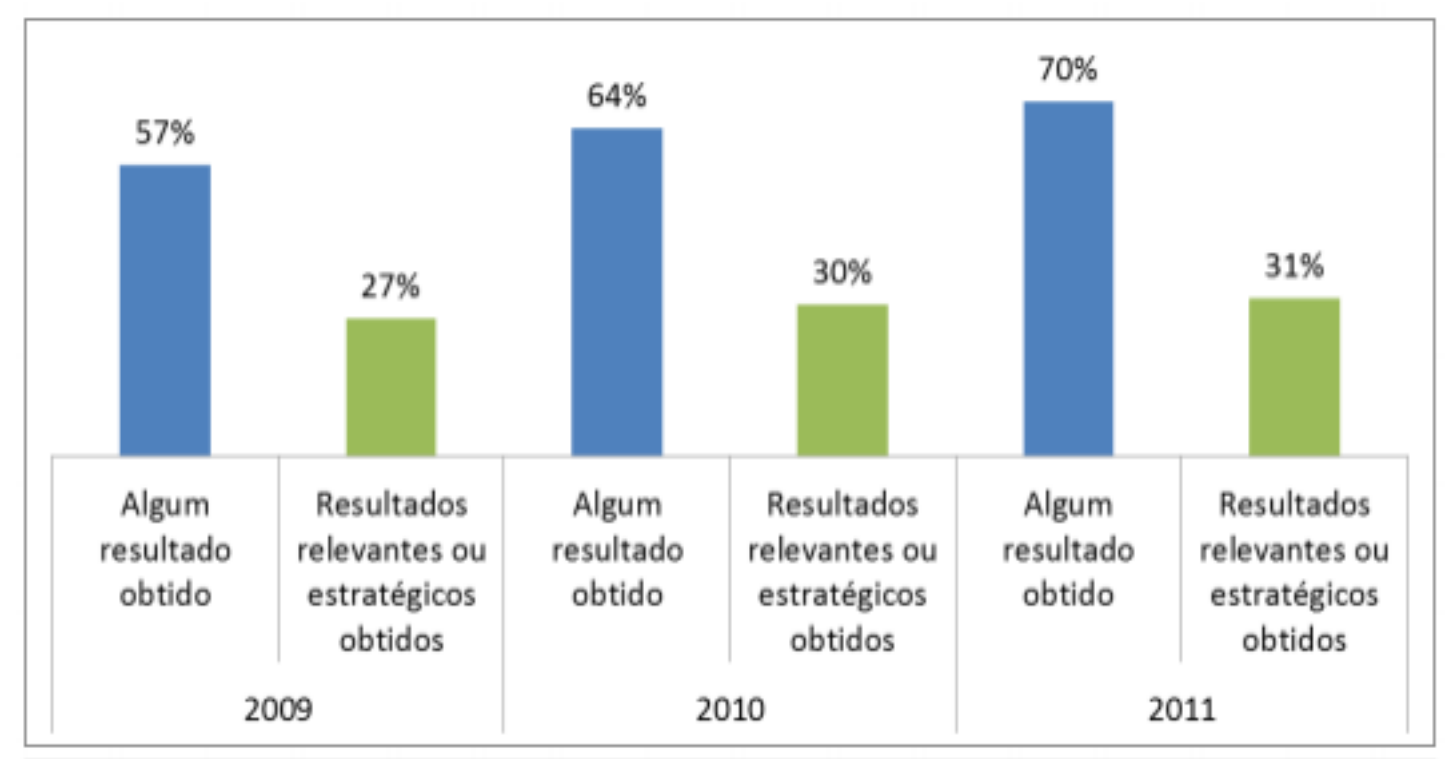

Figura 1: Resultados obtidos com BPM

Fonte: Pesquisa “A Evolução do BPM nas Organizações Brasileiras“ - (ELO GROUP, 2015) 
Outro ponto interessante a ser ressaltado é que, enquanto mais da metade das empresas estudadas pela pesquisa esperavam ter resultados relevantes, apenas um terço delas teve suas expectativas atendidas. Ainda segundo a pesquisa, em 2009, $27 \%$ das empresas apontaram resultados relevantes obtidos com as práticas de BPM, em 2010 e 2011 o número cresceu muito pouco, conforme mostra a Figura 2: Comparativo entre resultados obtidos x resultados esperados.

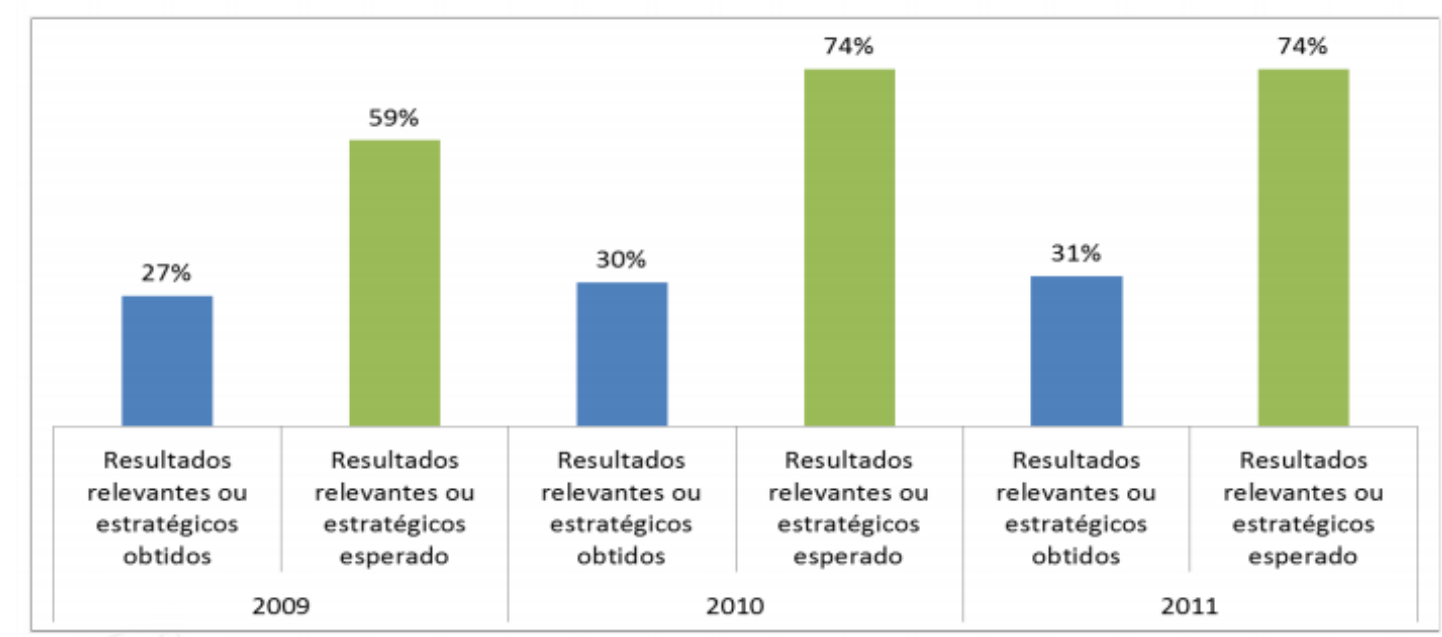

Figura 2: Comparativo entre resultados obtidos $\mathrm{x}$ resultados esperados

Fonte: Pesquisa “A Evolução do BPM nas Organizações Brasileiras" - (ELO GROUP, 2015)

A pesquisa aponta, ainda, que um dos motivos dos números não terem um aumento expressivo é a falta de alinhamento entre as atividades operacionais e de baixo valor agregado com as estratégias da organização.

Olhando mais especificamente as MPE's (micro e pequenas empresas), o desafio é ainda maior. Para se tornarem competitivas MPE's tem que adotar atividades inovadoras que as diferenciem da concorrência, além de conseguir suprir as necessidades de cada cliente.

A crescente importância de novos métodos de mensuração e avaliação de eficiência de uma empresa em entregar resultados positivos para seus clientes e investidores faz com que MPE's tenham que estar sempre se atualizando para se manterem competitivas no mercado. Portanto, o presente trabalho pretende analisar o processo de venda de uma microempresa de limpeza de superfícies do Rio de Janeiro, fazendo um mapeamento da área e respondendo quais são os pontos críticos que precisam ser controlados. 


\section{2 - Objetivo do Estudo}

O objetivo principal do presente estudo é mapear o processo de venda desta microempresa e identificar os pontos críticos que precisam ser controlados pelos seus sócios para aumentar a eficiência da área.

\section{3 - Objetivos Intermediários do Estudo}

Para alcançar o objetivo final do estudo é preciso seguir algumas etapas. São estas, modelagem do processo de venda, identificação dos pontos críticos, definição de métricas para análise e sugestão de melhorias.

\section{4 - Delimitação e Foco do Estudo}

O único processo que o estudo analisará será o de venda da prestação de um serviço de limpeza. Este processo, entretanto, abrange as três principais áreas da empresa (operacional, financeira e comercial) que participam paralelamente desde o primeiro contato com o cliente, até a finalização do trabalho e o serviço pós-venda. NO ão será objeto deste estudo o cálculo das margens e custos de cada operação nem as estratégicas logísticas adotadas pela empresa para a otimização de seu lucro. Processos nas tomadas de decisão, referentes ao marketing e contabilidade tampouco serão analisados.

\section{5 - Justificativa e Relevância do Estudo}

A principal motivação para o estudo foi a percepção de um dos sócios da falta de procedimentos de controle dentro da empresa e a falta de sinergia entre as áreas comercial e operacional, que acaba por minar a eficiência do processo de venda. Desta forma, tornando-se essencial a padronização de todas as etapas deste processo. $\mathrm{O}$ presente estudo poderá contribuir também como base para futuros empreendedores e/ou alunos que queiram entender melhor como funciona a elaboração e implementação de procedimentos de controle e padronização dentro de uma pequena empresa. 


\section{2 - Referencial Teórico}

Neste capítulo são apresentados os resultados da pesquisa realizada em materiais secundários que se relacionam com o tema abordado na presente investigação monográfica. As conclusões deste estudo serviram de base para a implementação de procedimentos operacionais padrões na microempresa analisada.

\section{1 - BPM - Business Process Management}

O Business Process Management (BPM), ou a Gestão por Processos, é uma metodologia iniciada na década de 90 que busca proporcionar aos diretores de uma determinada organização um maior controle através da combinação de técnicas de gestão administrativa e tecnologia da informação. Conforme apontado pela Venki, empresa especializada na automatização de processos via BPM, trata-se de uma abordagem estruturada onde os processos internos da organização estão em foco. É um método de gestão que analisa de forma contínua todos os procedimentos realizados pela companhia e, ao longo do tempo, vai implementando mudanças e elementos novos, afim de agregar valor para a mesma. A gestão por processo oferece ferramentas de suporte ao planejamento, implantação, gerenciamento e análise à companhia.

Segundo Gart Capote (2007), referência internacional em BPM, o "Gerenciamento de Processos de Negócio é uma abordagem interdisciplinar para identificar, desenhar, executar, documentar, medir, monitorar, controlar e melhorar processos de negócios, automatizados ou não, para alcançar resultados consistentes e alinhados com os objetivos estratégicos da organização" (CAPOTE, Gart - BPM Para Todos; p 37). Assim, serve como ferramenta para aprimorar a forma como os negócios são realizados e as organizações geridas.

Outra definição do BPM, segundo o CBOK - principal livro de referências sobre esta metodologia é: "Uma disciplina de gerenciamento e um conjunto de tecnologias que provê suporte ao gerenciamento por processo. Uma convergência de tecnologias 
de fluxo de trabalho, integração de aplicações corporativas, gerenciamento de desempenho e logística, apresentadas com foco no suporte ao gerenciamento baseado em processos" (BPM CBOK, V3.0, 2013, p.62)

O BPM não descreve apenas o processo de negócio através de máquinas, tarefas e pessoas, também inclui o consumo de recursos, descrição de custos e tempo necessário para cada um de seus componentes. Permitindo, assim, uma simulação mais crível dos possíveis cenários, gerando métricas de avaliação mais precisas. Desta forma, na comparação destes cenários tem-se situações mais semelhantes à vida real, facilitando a criação de um sistema de informação automatizado.

Segundo Baldam et al. (2009) o clico do BPM é composto por quatro fases: Planejamento, modelagem e otimização de processos, execução dos processos e controle e análise de dados. A Figura 3 - Ciclo do BPM, ilustra estas quatro fases.

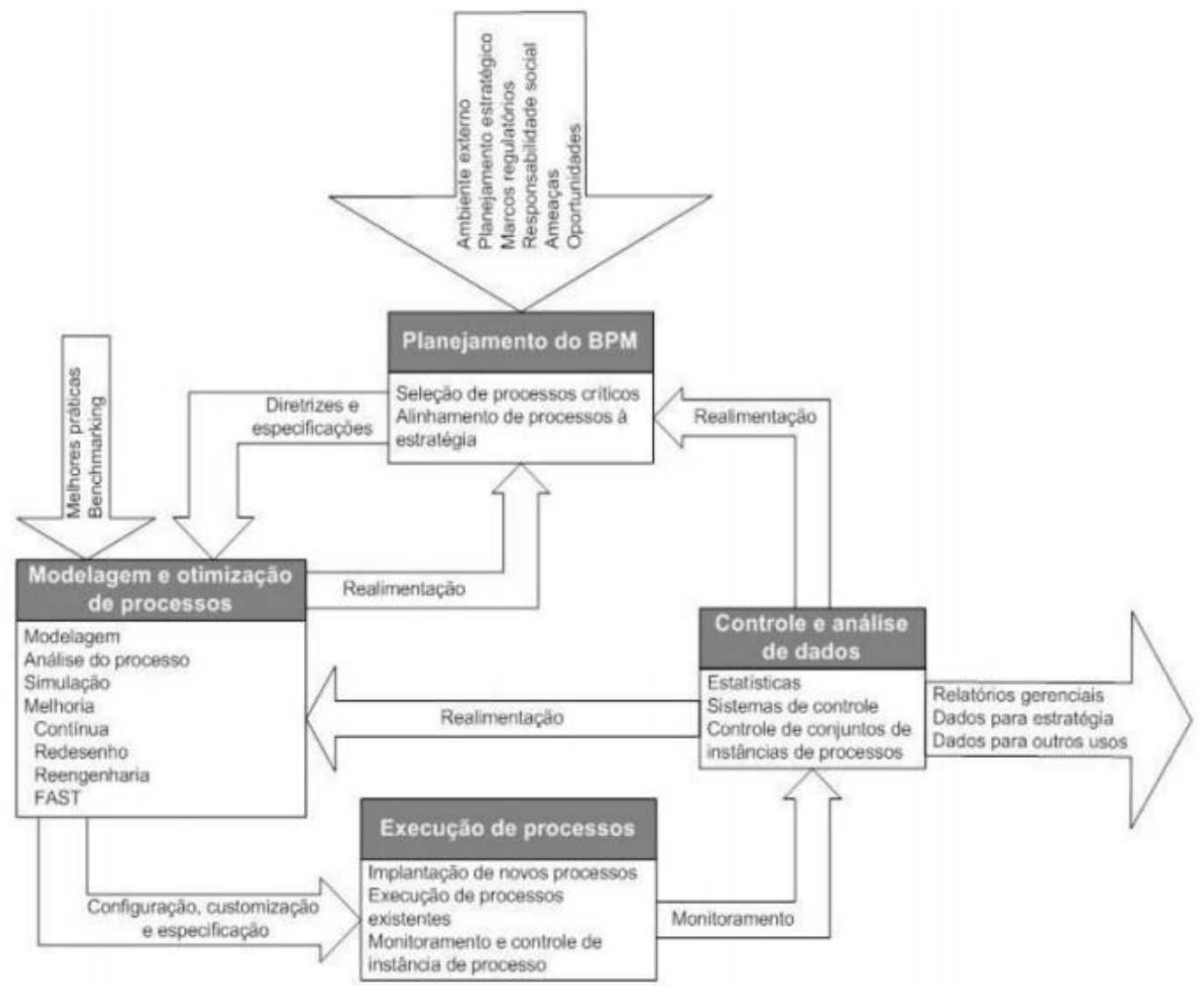

Figura 3: Ciclo do BPM

Fonte: http://www.synergo.es/expert-erp-bpm/ 
$\mathrm{Na}$ etapa de planejamento são definidas quais as atividades-chave para a estratégia da organização e levantadas as falhas que possam causar danos à realização do processo. É quando o plano de ação da empresa é estruturado e se analisa a hierarquia dos processos para ver qual deles precisa de uma ação imediata. Para Davenport (1994), antes da implantação e gerenciamento, é necessário alinhar o processo de negócio de forma que atenda os objetivos táticos e estratégicos da empresa.

Na segunda etapa, isto é, na modelagem e otimização de processos, é quando todos os processos são documentados e compreendidos a fundo, quanto a seus custos, recursos necessários, tempo percorrido durante a ação etc. Esta é a fase mais visível do BPM, que começa a comparar a forma atual da empresa de realização de suas atividades-chave (As is), para a forma que a empresa pretende vir a estar realizando estes processos (To be).

A execução de processos se dá através da implementação de atividades que garantirão que a forma dos processos a serem realizados seja a otimizada na etapa anterior. É quando se dá a transferência de tecnologia, ajustes de equipamentos e um primeiro acompanhamento de controle de todos estes processos.

E por último vem a fase de controle e análise de dados. Por mais que esta seja a fase onde o controle está em foco, o ideal é que o mesmo esteja presente em todas as etapas do BPM, desde o planejamento até a análise de dados. Nesta etapa é vital o uso de indicadores que gerem informações a respeito do andamento da cadeia como um todo e também de cada processo em si.

\section{2 - Processo}

O termo "processo" pode ter diversos significados a depender da área de atuação em que o mesmo está sendo observado. No Direito, segundo o Instituto Geral de Educação, Ciência e Tecnologia, um processo administrativo é um "Procedimento destinado a apurar responsabilidade de servidor por infração praticada no exercício de suas funções ou relacionada com as atribuições do seu cargo e a ele estão sujeitos todos os servidores públicos estatutários". Conceito este, que difere completamente do âmbito da Engenharia, que trata processo como sendo o mapeamento sistemático das operações de uma determinada ação para que esta possa ser realizada. 
Para a Administração, o conceito de processo está mais vinculado à forma pela qual as tarefas da organização são realizadas. E como toda organização possui tarefas diversas que devem ser realizadas, conclui-se assim, que toda empresa possui processos.

Não importa o tamanho, setor, tempo de vida, toda organização possui determinados processos que devem ser realizados para a obtenção dos resultados esperados pela mesma. Segundo o guia BPM CBOK (2013, pág. 35), o processo é "uma agregação de atividades e comportamentos executados por humanos ou máquinas para alcançar um ou mais resultados“.

Como tratado em diversos cursos de Administração de Empresas, as quatro principais funções do administrador são a de planejar, organizar, dirigir e avaliar as atividades dentro da empresa. $\mathrm{O}$ que está totalmente relacionado com a gestão de processos. Para Rebouças (2007, p.58) processo é “o conjunto estruturado e intuitivo das funções de planejamento, organização, direção e avaliação das atividades sequenciais, que apresentam relação lógica entre si, com a finalidade de atender e, preferencialmente, suplantar, com minimização dos conflitos interpessoais as necessidades e expectativas dos clientes externos e internos da empresa."

É valido ressaltar também que, segundo Gonçalves (2000), todo e qualquer processo precisa ter como foco principal o cliente, seja ele um cliente final externo à empresa ou até mesmo um departamento interno da organização. A implementação de processos dentro da organização visa, entre outros resultados, acrescentar valor para o cliente e também para a empresa, facilitando tomadas de decisão, aumentando a qualidade de dados e informações gerenciais, otimizando tarefas, etc. Para isto, muitas vezes as organizações adotam o que chamamos procedimentos operacionais padrões, os POP's.

\section{3 - Procedimento Organizacional Padrão (POP's)}

O procedimento operacional padrão, mais conhecido como POP, é uma descrição detalhada, de fácil entendimento, de todos os processos e operações necessárias à realização de uma determinada tarefa. Ou seja, é um roteiro com procedimentos padronizados para a execução de uma atividade. 
Este roteiro expressa basicamente o planejamento de um trabalho repetitivo que deve ser usado, na maioria das vezes, por pessoas da área operacional da empresa. Ele contém instruções sequenciais das operações; quais peças devem ser verificadas, quais materiais devem ser usados etc. Isto minimiza o risco de erro humano nas operações fundamentais da empresa e aumenta a previsibilidade de resultados da organização.

Pode parecer uma tarefa simples a elaboração de um POP, porém diversas variáveis particulares da empresa devem ser levadas em consideração. Portanto um POP não pode ser copiado de uma empresa para a outra mesmo que ambas sejam similares em questão de tamanho, setor de atuação etc.

Outro ponto importante que vale ser ressaltado na hora da elaboração do roteiro, é a necessidade da colaboração da pessoa que estará efetuando a tarefa. É imprescindível que o colaborador tenha total entendimento de todos os passos e etapas que devem ser seguidas.

Além disso, uma organização deve estar sempre realizando análises críticas sobre a aplicabilidade destes procedimentos. Muitas vezes mudanças externas à organização forçam a mudança na forma de executar tarefas, processos internos, entre outros. Portanto estas análises são fundamentais para verificar se os POP's ainda geram algum tipo de vantagem competitiva para a empresa, caso contrário, os mesmos devem ser alterados e atualizados para continuar obtendo um determinado resultado esperado.

\section{4 - Padronização}

O ponto central dos procedimentos operacionais padrões, como o próprio nome já diz, é sua padronização. Isto é, são pequenos processos executados pela organização que devem ser feitos sempre da mesma forma (padronizados), afim de garantir que os resultados sejam sempre os mesmos.

Este tipo de procedimento é muito comum no ramo de franquias, onde os franqueados devem se submeter aos mesmos processos operacionais do franqueador afim de garantir que todos tenham a mesma forma de atuação para que o cliente reconheça a marca e o produto/serviço em qualquer uma das franquias. 
A padronização busca organizar e normatizar procedimentos operacionais de trabalho de maneira que aumente a produtividade da organização, fazendo com que o produto final atenda às expectativas dos clientes de maneira simples, com uma menor variação entre os resultados e um menor custo para a empresa. Além destes benefícios, há também muitos outros, como por exemplo: permite otimizar a utilização dos recursos disponíveis, beneficia a operacionalização do processo, garante a qualidade dos produtos finais e também facilita o controle de todo o processo de manufatura e venda do produto.

Desta forma, a padronização traz inúmeros benefícios para a organização e deve ser visto como algo vantajoso para todos os stakeholders da empresa - diretores, fornecedores e clientes. Pois, além de simplificar a execução das tarefas operacionais, dá mais espaço para seus executivos pensarem em questões estratégicas para o crescimento da organização.

Além disso, um sistema de padronização é fundamental para a empresa que deseja implementar sistemas de gestão baseados na qualidade, como por exemplo o ISO 9001. Isto assegura à empresa que, através de sua implementação, todos os processos e atividades serão executados seguindo as regras pré-definidas à risca.

\section{5 - Reengenharia}

Na década de 90, segundo o site História da Administração, os americanos Michael Hammer e James Champy, considerados "pais" desta teoria, criaram o conceito como sendo a "reorganização radical sistemática dos processos empresarias de toda uma organização, função e processo".

Esta teoria se consolidou ao longo dos anos como sendo um redesenho dos processos de uma determinada organização afim de alcançar melhorias em suas três principais áreas: custos, serviços e tempo. Ela busca a fusão de tarefas, e eliminação de quaisquer processos não-fundamentais à empresa, uma maior autonomia no corpo funcional da companhia, e a descentralização das tomadas de decisões. Sua implementação se dá em quatro fases. São elas: 
1. Preparação: fase inicial onde são listados todos os processos da empresa, selecionando os que serão redefinidos.

2. Planejamento: fase onde é planejada e implementação da reengenharia. Nesta fase é feita a análise de tempo gasto por tarefa, estrutura de custo, pessoal necessário entre outros e pensa-se em como alterar estas tarefas afim de aumentar a eficiência e eficácia dos processos.

3. Implementação: fase de implementação dos processos reinventados

4. Avaliação: fase final da implementação onde é feita a análise e mensuração dos resultados das alterações implementadas e onde são feitos todos os ajustes necessários. 


\section{Método Escolhido para a Coleta e Processamento de Dados}

\subsection{Métodos de Pesquisa Utilizados}

A pesquisa deste trabalho é de natureza aplicada, pois foi realizada com o intuito de solucionar uma situação específica e de método qualitativo, onde os dados são obtidos através da interpretação de respostas abertas e de documentos e fluxogramas confeccionados pela empresa estudada. Segundo CRESWELL (1997), a pesquisa qualitativa é um processo de busca do entendimento que explora um problema, exatamente o que o estudo pretende fazer. Já para Vergara (1997), existem dois tipos de critérios de qualificação para uma pesquisa os fins, e os meios.

Quanto aos fins, a pesquisa é descritiva, onde o processo estudado foi desenhado para que fosse feita uma análise da rotina de venda e a identificação de seus pontos críticos.

Já a respeito aos meios, a pesquisa é um estudo de caso envolvendo uma microempresa no setor de limpeza.

\subsection{Procedimentos e Instrumentos de Coleta de Dados}

O presente estudo foi elaborado com intenção de identificar e sugerir possíveis melhoras processuais no modelo de venda de uma microempresa de limpeza de fachadas. Para isto, foi necessário entender como era a abordagem dos colaboradores da área comercial da companhia e suas ramificações. Precisaram ser aprofundadas também questões relacionadas ao gerenciamento de mudanças, modelagem do processo e melhorias continuas almejadas e implementadas pelos sócios.

A coleta de dados foi feita através da avaliação do processo atual e de entrevistas com todos os envolvidos na venda. Assim, foi possível fazer o mapeamento do processo, analisar quais as dificuldades encontradas pelos colaboradores e identificar aonde estão as oportunidades de melhorias. 
Também se utilizou fontes de informações secundárias para o estudo. Foram usados artigos acadêmicos, dissertações e pesquisas já elaboradas que se relacionavam com o tema estudado.

Para a coleta de dados foram efetuadas entrevistas semiestruturadas com cada um dos sócios da companhia (já que todos fazem juntos a área comercial), e também com o gerente da microempresa, pois a área de vendas depende da visita técnica e expertise do colaborador para enviar os orçamentos e calcular os custos do serviço. As entrevistas foram realizadas entre 24 de abril e 03 de maio e tiveram duração de cerca de 20 minutos cada.

Os entrevistados expressaram seus pontos de vista quanto a falta de eficiência em algumas etapas do processo e da lentidão para a conclusão do processo de venda devido a necessidade de análise dos dados pelo gerente da empresa. Além disso, com o fluxograma do processo de venda (criado pela empresa e apresentado abaixo - Figura 5: Fluxograma inicial) impresso em mãos, foi possível que os entrevistados avaliassem quais os pontos críticos do processo e sugerissem melhorias.

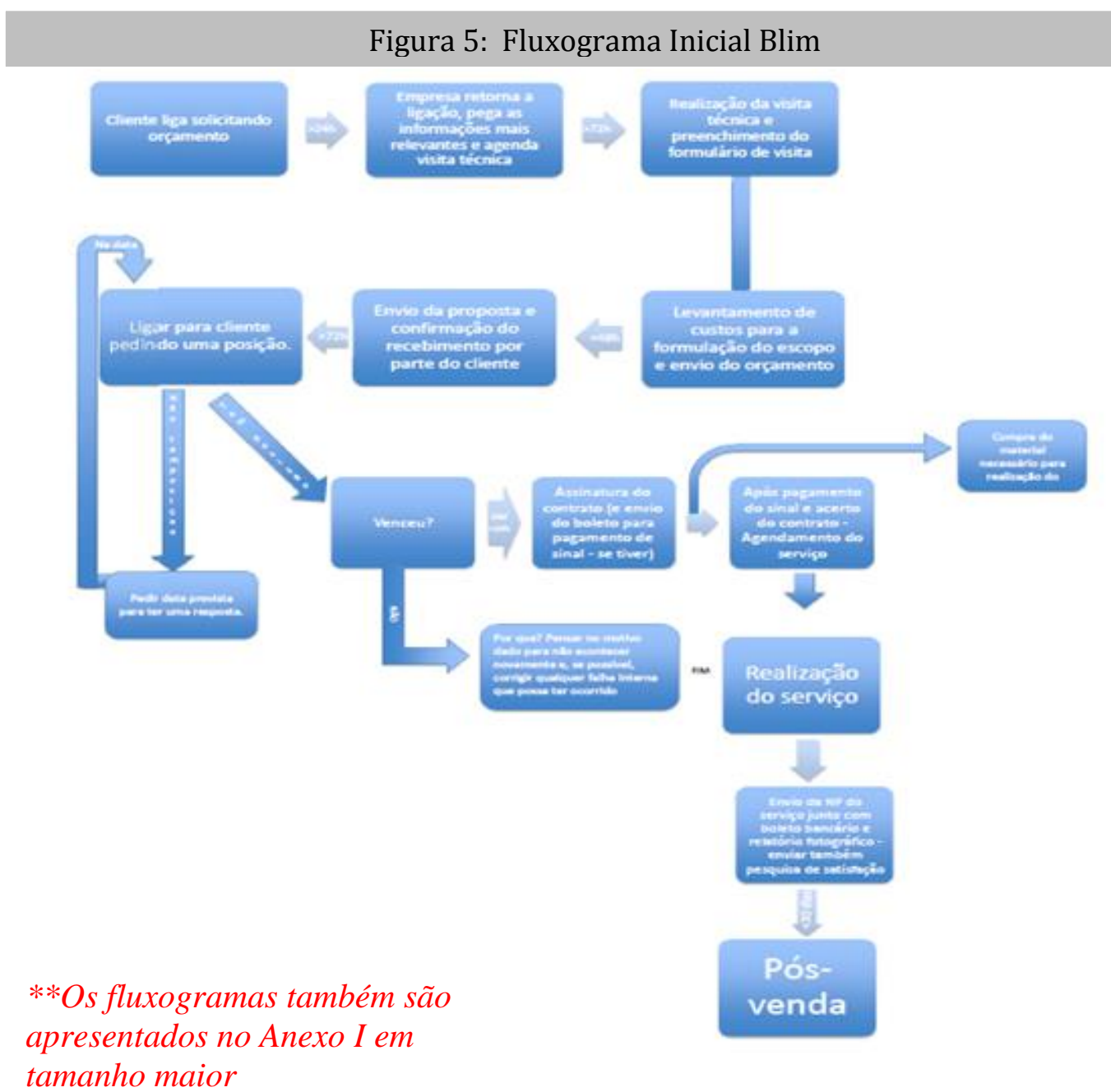


Desta forma, os entrevistados foram convidados a responder as seguintes perguntas:

1. O que você entende como venda?

2. Qual parte do processo de venda da empresa você acha que é o mais importante? E o menos?

3. Como você imaginaria o como sendo o processo de venda, etapa por etapa?

(Mostra o fluxograma inicial)

4. Você acha que este fluxograma demonstra bem o processo de venda?

5. Qual etapa do processo você acha que ocorre mais erros durante a venda do serviço?

6. Quais melhorias você daria para o atual processo?

7. Você conseguiria redesenhar o processo da forma que você julga melhor?

8. Como você considera sua participação ao processo?

Após o cruzamento das informações provenientes das entrevistas, algumas etapas foram modificadas e certas atividades também tiveram a forma de serem realizadas alteradas. Um novo modelo foi feito e é apresentado no Anexo I.

\subsection{Formas de Tratamento e Análise de Dados}

Após transcritas, as entrevistas realizadas foram analisadas diversas vezes afim de se obter informações sobre todo o processo de venda da microempresa para se detectar possíveis falhas. As informações fornecidas pelo gerente e os sócios foram cruzadas com o referencial teórico e, a partir deste cruzamento de dados, foi possível identificar quais pontos críticos do processo precisam de um controle maior por parte dos sócios e quais devem ser mudados e/ou melhorados. 


\subsection{Limitações do Método}

Apesar de julgar o método escolhido ser o mais eficaz para o presente estudo, é possível que algumas informações tenham sido ocultadas pelos entrevistados. Isto porque por se tratar de sócios que são muito amigos fora do ambiente de trabalho, percebeu-se um certo desconforto entre todos eles na hora de apontar o responsável por algum erro ou falha do processo. Além disto, pelo autor do presente estudo também ser um dos sócios da empresa é possível ter havido um viés não percebido, mesmo com todos os esforços de minimizar este viés.

A pesquisa qualitativa tem como objetivo conhecer a qualidade do processo estudado. Além de permitir explorar o tema estudado com maior profundidade sem que haja um grande número de entrevistados. Outro ponto positivo que levou a escolher este método foi o fato dele permitir flexibilidade quantos as respostas dadas, dessa forma foi possível identificar exatamente o que cada um dos entrevistados pensava a respeito de todas as situações perguntadas.

Um dos pontos negativos do método é que não podemos generalizar as respostas devido ao pequeno número da amostra, quantifica-las e o fato das respostas não serem fechadas. Entretanto, visto que o estudo é a respeito de uma microempresa, com um número pequeno de colaboradores e pouco tempo de vida, acreditou-se que este método era o melhor para o estudo. 


\section{Apresentação e Análise dos Resultados}

\subsection{A Empresa e o Mercado}

Os ramos de limpeza e segurança, segundo a SEBRAE, são os de maior índice de terceirização entre as organizações brasileiras. Isto porque normalmente são serviços fora do core business das empresas, isto é, a serviços que não fazem parte da principal área do negócio da companhia. Portanto, através da terceirização destes serviços faz com que todo o efetivo contratado concentre seus esforços exclusivamente à sua principal área de negócio.

Considerando o ramo de limpeza, mais especificamente o de limpeza de fachadas (principal negócio da empesa objeto de análise), este é um setor ainda em desenvolvimento no Brasil, onde grande parte das empresas atuantes não fazem o uso de mecanismos de controle de qualidade ou de profissionais especializados.

O mercado de limpeza profissional do Brasil, em 2015, movimentou cerca de R \$ 17 bilhões de reais, enquanto neste mesmo ano, nos EUA, foram movimentados cerca de U\$ 40 bilhões, quase sete vezes mais (considerando a cotação atual do dólar à $\mathrm{R} \$ 3,30$ - abril/2017). Isto mostra que este mercado ainda tem muito a ser desenvolvido no território brasileiro.

Além disto, segundo dados da ABRALIMP - Associação Brasileira de Limpeza Profissional - a maioria das empresas de limpeza do Brasil possuem menos de dez anos de vida, e $95 \%$ possuem até cinco funcionários.

Outro dado que chama a atenção é o de que $90 \%$ destas empresas surgem com profissionais não especializados e sem formação acadêmica. Mostrando um alto grau de amadorismo no setor. A microempresa estudada neste trabalho atua neste setor e foi criada em 2015. Apesar de ter começado prestando única e exclusivamente o serviço de limpeza de fachadas, hoje já possui mais de dez diferentes serviços relacionados à limpeza e manutenção predial dentro de seu portfólio e uma cartela de clientes que varia entre lojas, concessionárias, shoppings, supermercados, e centros empresarias. Dentre os serviços prestados pela empresa estão: limpeza de fachadas (de qualquer tipo de superfície), Remoção de calcificação de concreto em vidraças, rejuntamento de 
silicone, limpeza de pisos, limpeza de pedras, limpeza de toldos e letreiros, limpeza de mármore, pintura comercial, serviços em altura e revitalização de superfícies e fachadas

Esta expansão rápida, entretanto, causou uma desorganização na padronização dos serviços prestados e, consequentemente, uma falta de controle dentro de sua área de vendas. A empresa ainda não possui um roteiro detalhado de quais procedimentos devem ser realizados durante o processo de venda de cada um dos serviços oferecidos, o que acarreta em dúvidas por parte dos colaboradores e uma perda de eficiência e velocidade nos serviços.

Além disso, com o crescimento da companhia e a demanda de seus clientes quanto à prestação de serviços adjacentes ao de limpeza de vidros (primeiro negócio pensado como core business da empresa) fez com que a companhia tivesse que mudar seu plano de negócios e adotar novos mecanismos e técnicas de prestação de serviço.

A Blim, ao longo de seus dois anos de vida, já faturou mais de $\mathrm{R} \$ 680.000,00 \mathrm{em}$ seus 92 serviços prestados. Hoje ela está situada em São Conrado e presta serviços em toda capital fluminense. Além de seus três sócios, conta com uma equipe de três funcionários, sendo eles um gerente e dois alpinistas industriais. Entretanto, seus custos elevados consomem a maior parte da receita gerada e a falta de planejamento nas operações acaba por atrasar a maior parte dos serviços.

\subsection{Perfil dos Entrevistados}

Por se tratar de uma microempresa, apenas o setor operacional tem seu colaborador definido, o gerente. Quanto aos sócios da empresa, apesar de cada um ter um foco em uma determinada área, todos participam de todos os setores de acordo com o necessário, até para ter uma visão holística do negócio. A Tabela 1 apresenta-se o perfil dos entrevistados. 


\section{Tabela 1 - Perfil dos Entrevistados}

\begin{tabular}{|c|c|c|c|c|}
\hline Nome & Foco & $\begin{array}{c}\text { Tempo de } \\
\text { empresa }\end{array}$ & Idade & \% de cotas \\
\hline E1 & Comercial & 2,5 anos & 28 & $35,50 \%$ \\
\hline E2 & Comercial & 1,0 ano & 23 & $35,50 \%$ \\
\hline E3 & Administrativo/Financeiro & 2,5 anos & 25 & $29,0 \%$ \\
\hline E4 & Gerente Operacional & 5 meses & 29 & $0 \%$ \\
\hline
\end{tabular}

Um ponto a ser ressaltado é que o autor deste trabalho também trabalha no processo pesquisado, portanto suas opiniões também foram levadas em consideração para a análise dos dados e proposta de melhorias.

\subsection{Análise dos Resultados}

As entrevistas foram fundamentais para conseguir validar o novo fluxograma. Para tentar obter melhores resultados para o presente estudo, todos os colaboradores da empresa foram entrevistados em um ambiente confortável e acolhedor já que as perguntas foram realizadas por um dos sócios (o que poderia causar certo desconforto). Ademais, foi analisado se todos tinham consciência de tudo que era necessário para tornar o processo de venda eficiente e se tinham consciência das restrições da empresa e das melhorias processuais que estavam constantemente sendo implementadas para ter-se uma melhora continua nas vendas da empresa.

Um dos primeiros fatores analisados foi o que cada um entendia como sendo uma venda. Imediatamente, todos responderam como sendo o ato de vender algo, e se aprofundaram na forma de vender um serviço.

Já na segunda pergunta, onde foi analisada a parte do processo de venda que cada um achava mais importante, as respostas variaram. Enquanto alguns achavam que a 
parte mais importante do processo era a hora da execução (prestação do serviço) outros responderam que achavam a parte de planejamento da venda era a que mais importa. Um ponto que foi levantado por todos foi a importância do pós-venda. Nenhum deu opinião sobre qual etapa seria a menos importante.

Após as perguntas introdutórias foi mostrado o fluxograma, inicialmente montado pela empresa, e perguntado a todos qual etapa do processo da venda cada um achava que ocorria mais erros (gargalos) na troca de informações. Nesta pergunta as respostas também variaram, o que mostra que gargalos ocorrem em diversas etapas do processo.

Os entrevistados demonstraram grande interesse pelo fluxograma falando que o mesmo era muito importante para que todos soubessem exatamente como funcionava a área de vendas da empresa. O único que apresentou considerações sobre o fluxograma quanto a necessidade de segregação das três áreas atuantes no processo foi entrevistado E3.

Um ponto interessante levantado por E4 quando perguntado sobre seu engajamento no processo de venda, foi o seu argumentou que dava o máximo para fazer com que a empresa estivesse sempre crescendo e prosperando, enquanto os sócios, E1 e E2 admitiram que poderiam estar fazendo muito mais para que o negócio desse certo. Uma das frases marcante durante as entrevistas é apresentada a seguir:

"Eu reconheço que eu poderia estar fazendo muito mais e sei que o E3 sempre levou a empresa nas costas. Tive um tempo pra refletir e ví que hoje eu devo dar entre 10 à $15 \%$ do que eu posso pra empresa, se eu der só metade (50\%) do meu potencial a empresa já vai longe! ” (E1)

\subsection{Mapeamento do Processo Atual (As Is)}

Com base nas informações levantadas, foi realizado um mapeamento de todo o processo de venda da empresa. Utilizando o sistema Lucidchart foi desenvolvido um novo e mais robusto fluxograma para o processo estudado, no qual todos os envolvidos foram convidados a dar suas respectivas opiniões afim de torná-lo o mais próximo à realidade possível. O modelo permitiu que os sócios visualizassem de forma mais rápida o processo como um todo e a partir dele identificassem mais uma vez os pontos 
críticos que poderiam ser melhorados. O Anexo I mostra a comparação entre os dois fluxogramas.

O novo fluxograma segrega cada uma das três áreas envolvidas no processo de venda (operacional, financeiro e comercial) e mostra a correlação das atividades realizadas por cada uma delas para que a venda ocorra. Como o marketing é externo (terceirizado) e feito apenas através de campanhas no Google (Google ad words) não há presença da área de marketing no processo de venda, que começa diretamente com o comercial.

\subsection{1 - Etapa 1: Colheita de Informações e Agendamento da Visita}

O processo se inicia quando um cliente potencial liga para o número da empresa e a secretária (também terceirizada) anota as informações do cliente. Após esse primeiro contato a secretaria manda um e-mail para os sócios da empresa para que eles retornem e peguem todas as informações necessárias para a realização de uma visita técnica (etapa 2 do processo).

\subsection{2 - Etapa 2: Realização da Visita Técnica}

Depois de coletar as informações do cliente e saber qual serviço o mesmo precisa é realizada uma visita técnica, onde os sócios e/ou gerente vão ao local para averiguar a situação do empreendimento a ser lavado. $\mathrm{Na}$ visita são tiradas fotos do local e preenche-se uma ficha de prospecção, elaborada pela empresa. Feita a visita, as informações são enviadas para o grupo de WhatsApp da companhia para que todos saibam como foi a prospecção e possam argumentar sobre o empreendimento quanto a custos, prazos e dificuldades. Somente depois de receber um feedback por parte do gerente que o orçamento começa a ser elaborado (etapa 3). Vale ressaltar que na maioria das vezes o gerente não está presente durante a primeira visita já que sua principal função é a de supervisionar a equipe, tendo que estar presente full-time em todos os serviços prestados. 


\subsection{3 - Etapa 3: Levantamento de custos e envio do orçamento:}

Recebido o feedback e levantado os custos os sócios enviam o orçamento para o cliente e pedem a confirmação do recebimento. Após no máximo 72h, caso não tenha havido algum retorno do contratante, os sócios ligam novamente para o cliente pedindo uma posição, em todas as vezes que os sócios tiveram que ligar para pedir um feedback quanto ao orçamento enviado o mesmo foi negativo.

\subsection{4 - Etapa 4: Formalização de Contrato e Documentações:}

Uma vez aprovado, dá-se início a etapa 4, onde confecciona-se um contrato de prestação de serviço atendendo todas as solicitações do cliente e os pré-requisitos impostos pela empresa. Normalmente a empresa trabalha com um sinal de 50\% do valor do orçamento - para aquisição de material e mobilização da equipe - e o restante varia de acordo com o cada contrato, desde pagamentos para 7 dias após o faturamento do serviço, até parcelamentos em duas ou três vezes.

A partir do momento que o orçamento é aprovado as áreas operacional e financeira entram no circuito. Enquanto a financeira prepara o boleto a ser enviado para o cliente, o operacional alinha com o comercial as datas possíveis para a prestação do serviço e cabe aos sócios programar com o cliente a data correta para início das operações. A partir do momento que o sinal (50\% do valor do orçamento) entra para a empresa o financeiro libera parte do valor para que seja comprado tudo que for necessário para a prestação do serviço, iniciando a $5^{\text {a }}$ etapa do processo.

\subsection{5 - Etapa 5: Planejamento e Mobilização do Operacional:}

A quinta etapa é a principal de todo o processo de venda, é nela que a equipe se prepara para a prestação do serviço e adquiri tudo o que for necessário para a limpeza, desde detergentes químicos e panos, até plataformas e emissão de documentos de segurança do trabalho. Nesta etapa o cronograma inteiro é revisto minuciosamente, afim de garantir que os prazos sejam atingíveis e os materiais adquiridos suficientes. Tudo deve ser feito de forma alinhada para garantir que a limpeza saia exatamente conforme acordado, até que chegue a data da prestação do serviço, etapa 6 . 


\subsection{6 - Etapa 6: Prestação do Serviço:}

A etapa 6 é a execução. O serviço deve ocorrer conforme estabelecido em contrato com todas suas clausulas sendo respeitadas, isto é, a equipe deve estar devidamente preparada, uniformizada, com os equipamentos e materiais necessários à limpeza e pontualmente no local determinado. Se qualquer um dos itens citados acima não estiver sendo cumprido, pode causar uma certa frustação no cliente que, futuramente, venha a significar a perda de vendas ou danos institucionais. Para garantir tudo isto, preenche-se uma ficha de ocorrência, onde todas informações relevantes ao serviço são imputadas diariamente, a ficha deve ser sempre assinada por um funcionário do contratante (além de pelo gerente da contratada) afim de respaldar a empresa sobre as informações ali contidas. Para que tudo saia de acordo com o planejado, é fundamental o planejamento minucioso realizado na etapa 5 .

\subsection{7 - Etapa 7: Pós-venda e Feedback}

Uma vez concluído o serviço é emitido, além da Nota Fiscal, um relatório de serviço. Como a prestação de serviços com alpinismo depende também de condições meteorológicas favoráveis (e isto está devidamente expresso nos contratos), este é um dos itens que muitas vezes atrasam cronogramas e devem estar devidamente informados nos relatórios. Além disso há também fotos de comparação antes $\mathrm{x}$ depois do empreendimento, facilitando a visualização por parte do cliente do resultado da limpeza. Esta é a última etapa do processo de venda atual. 


\section{Conclusões}

Após analisar o processo de venda da empresa repetidas vezes, desde a primeira ligação do cliente potencial até o envio da nota fiscal e do relatório pós serviço foram descobertos alguns pontos do processo que podem ser melhorados. Apesar de não parecer um processo complicado, a venda de um serviço nunca é simples. O planejamento é parte fundamental para que tudo seja feito corretamente. Por se tratar muitas vezes de serviços realizados em altura, todo risco deve ser minimizado.

Desta forma, foram feitas diversas anotações, cruzando as informações com o referencial teórico, afim de garantir que todas as sugestões fossem fundamentadas nas mais variadas técnicas de gestão do mercado.

Após este cruzamento de dados foi verificado que diversos dos processos internos não eram feitos de forma sincronizada e que muitas vezes gargalos durante a troca de informação prejudicavam a eficiência da empresa e consequentemente sua capacidade de gerar lucro. As conclusões e recomendações são apresentadas a seguir.

\subsection{Pontos Críticos do Processo de Venda}

O primeiro ponto crítico verificado foi em relação aos agendamentos das visitas técnicas. A área comercial da empresa não possui uma agenda onde os sócios possam ver as visitas programadas para a semana ou para o mês. De acordo com as entrevistas, os agendamentos são anotados em folhas de papel com as visitas de cada um, e cada sócio leva consigo este papel para garantir que não se esqueçam de seus compromissos. Ultrapassada, esta forma de gestão dificulta o controle dos agendamentos e impossibilita a visão completa de todas as visitas agendadas e realizadas.

O segundo ponto crítico levantado pelo estudo foi na hora de imputar as informações da visita técnica e do cliente potencial no sistema da microempresa. Foi 
verificado que este processo simplesmente é deixado de lado. Assim a Blim não tem nenhuma base de dados quanto aos clientes que alguma vez pediram um orçamento.

Este é um dos pontos mais importantes apurados pelo estudo. Uma base de dados precisa permitiria que os sócios conseguissem acessar as informações de seus clientes de forma rápida. Segundo Gart Capote (2007), o controle e monitoramento das operações é um dos pontos mais relevantes do BPM, pois é ele que permite quantificar resultados para averiguar a necessidade de mudanças organizacionais e estratégicas. Porém, como não há o armazenamento destas informações, quando perguntados sobre a data de realização de uma visita técnica, ou quando foi enviado um determinado orçamento, nenhum dos colaboradores sabia responder de forma rápida e precisa. Quando analisado o porquê de não haver esse sistema de informações, mais uma vez os sócios da área comercial não souberam responder. A Blim possui um sistema ERP contratado chamado NIBO, que serve exatamente para controlar o fluxo de caixa da empresa e gerir a parte comercial através de seu CRM (Customer Relationship Management) integrado. A parte do CRM, entretanto, não é feita. A falta de uma base dados sólida resulta em um dos maiores problemas que a empresa sobre hoje em dia, a dificuldade de fazer o pós-venda.

Um bom pós-venda não só mantem clientes fidelizados, mas também aumenta o valor institucional do nome da marca. Além das vantagens intangíveis, pesquisas hoje em dia mostram que manter um cliente antigo custa cerca de cinco vezes menos que criar um novo - É o que mostra a pesquisa realizada pelo site Portal Educação. Sem uma base de dados, entretanto, fica extremamente difícil de fazer um pós-venda periódico eficaz, pois não se sabe exatamente quando foram prestados os últimos serviços, nem quando realizados os últimos contatos.

Outro ponto extremamente relevante no processo analisado é quanto ao levantamento dos custos. Os sócios da empresa não possuem expertise no ramo de limpeza e nem know-how sobre os preços praticados, margens de lucro e produtos utilizados para cada serviço ofertado. Por causa disso, o levantamento de custos de cada serviço é concentrado no gerente, que muitas vezes não tem como responder os questionamentos dos sócios de forma rápida devido à sua dupla função de gerente, e alpinista.

Este é um dos pontos centrais da gestão por processo, conhecer o mercado e todos os processos relevantes à prestação de um determinado serviço. Sem que haja um estudo prévio de todos os desafios, formas de atuação e prestação do serviço 
dificilmente os sócios conseguirão otimizar seus resultados e tarefas conforme a técnica do BPM propõe.

A Blim hoje em dia possui nove clientes de contratos anuais com prestação de serviços mensais. Em seis deles a supervisão pelo gerente é obrigatória. Como a maior parte do tempo o gerente está auxiliando a equipe nestes contratos, não sobra tempo o suficiente para que ele esteja junto com os sócios para ajudá-los na formulação das propostas. O que atrasa esta etapa do processo de venda e resulta no envio de orçamentos errados com margens apertadas demais, ou largas demais que resultam na perda do serviço. Podemos ter uma noção melhor desta falta de coerência nos orçamentos enviados através da Tabela 2: Conversão de clientes.

Tabela 2 - Conversão de Clientes

\begin{tabular}{|c|c|c|c|}
\hline Preço do Orçamento & Enviados & Aprovados & \% de conversão \\
\hline$R \$ 100,0-R \$ 1.000,00$ & 53 & 21 & $40 \%$ \\
\hline$R \$ 1 ; 000,00-R \$ 5.000,00$ & 41 & 14 & $34 \%$ \\
\hline$R \$ 5.000,00-R \$ 10.000,00$ & 19 & 6 & $32 \%$ \\
\hline$R \$ 10.000,00<$ & 13 & 3 & $23 \%$ \\
\hline TOTAL & $\mathbf{1 2 6}$ & $\mathbf{4 4}$ & $35 \%$ \\
\hline
\end{tabular}

Antes de qualquer prestação de serviço, deveria ser feito um cronograma com as etapas do processo de limpeza juntamente com uma lista de todos os materiais e produtos necessários; nada disso é feito. A falta de planejamento e de tempo hábil para que a equipe se prepare para cada serviço resulta em serviços realizados de forma ineficiente, que além de causar atrasos no cronograma, muitas vezes provoca o retrabalho. Segundo Baldam et al. - mencionado anteriormente - a primeira etapa do processo de implementação do BPM, o planejamento, é a principal etapa de todo o processo, pois é nele que são definidas quais estratégias serão seguidas para a melhor forma de se realizar uma tarefa e quais os pontos críticos inerentes a sua realização.

Também não há uma base de dados quanto aos produtos e materiais em estoque, impossibilitando o controle de gastos de detergentes e outros insumos necessários às limpezas. 
Um dos principais problemas da Blim no momento atual é seu caixa. Devido ao acúmulo de dívidas de cartão de crédito e a falta de pagamento de impostos e prestadores de serviço, a microempresa usa a maior parte de seus recebimentos para o pagamento destes atrasos, acarretando na falta de recursos para a compra de insumos para a realização dos serviços. Como os pagamentos destes atrasos são realizados antes mesmos da prestação do serviço, gasta-se mais que o equivalente ao lucro líquido fazendo que o problema continue de forma ininterrupta. Para tentar reverter esta situação, diversas sugestões foram feitas e são apresentada a seguir.

\subsection{Sugestões de Melhorias (To Be)}

Conforme mencionado anteriormente, há diversos pontos do processo de vendas da Blim que necessitam ser reavaliados e melhorados. A primeira sugestão foi a de instauração de uma agenda compartilhada, para que todos saibam exatamente o que está acontecendo na área comercial. O preenchimento da agenda é um procedimento essencial para o monitoramento das visitas e a otimização do tempo de cada membro da equipe. Isto facilitaria a visão completa dos sócios quanto ao andamento da área de vendas, garantindo assim, conforme apontado por Paim (2009), a eliminação de barreiras e uma maior interação entre os diretores.

Apesar de não se dizerem resistentes à mudança, ficou claro ao longo do estudo que os sócios têm dificuldades em adotar novas tecnologias para o auxílio na execução de tarefas. Muitas delas são realizadas de forma arcaica com sistemas de folhas e pastas (físicas) ao invés do uso da tecnologia (arquivos digitais) para reduzir o desperdício e o uso de recursos desnecessariamente. Este é um ponto crítico pois, conforme abordado na pesquisa realizada pela Innovation Excellence Research, é mais fácil contornar a resistência a mudança quando este incentivo vem de forma top-down, ou seja, das esferas superiores para as mais baixas.

A principal crítica do estudo é quanto à falta de uma base de dados sobre todos os clientes existentes, e potenciais que por algum motivo não puderam ser atendidos. A base de dados é fundamental para que o serviço pós-venda seja feito. Não há qualquer organização de documentos e informações cadastrais dos clientes a não ser nos celulares dos sócios e nos e-mails da empresa. A sugestão mais importante que o estudo 
faz para a Blim é que seus sócios façam uma varredura retroativa completa de todos os serviços prestados e clientes que alguma vez solicitaram orçamento colocando seus respectivos dados no NIBO. A partir do momento em que todos estes dados estiverem no sistema será fácil dos sócios acessarem quaisquer informações necessárias e consequentemente realizar o monitoramento de seus clientes ativo afim de fidelizá-los. Finalizada a etapa retroativa, é recomendável que seja acrescentado o procedimento de colocação de dados de clientes de acordo com que apareçam novas solicitações.

Além de informações dos clientes, também é altamente recomendável que a empresa comece a utilizar o sistema ERP para controle de estoque e comparação de fornecedores, ambas funcionalidades já disponíveis no pacote contratado. Além das informações de clientes, também não constam informações de fornecedores de equipamentos, produtos e materiais o que acarreta no atraso do envio de propostas quando, no orçamento, deve haver a inclusão de custos de locação de plataformas e andaimes, por exemplo. Outro ponto que vale ressaltar é a falta de planejamento da empresa antes dos serviços. É fundamental que haja a preparação de um cronograma com um roteiro para todos os serviços que serão feitos. Alguns serviços prestados duram semanas e é vital que se tenha controle do que já foi realizado x o que falta ser feito. Através de um cronograma também fica mais fácil monitorar os resultados. Como a limpeza de áreas externas sofre influência direta de alterações climáticas, é vital que os supervisores do contratante acompanhem diariamente os resultados parciais do serviço.

Fazer uma comparação de preços também é crucial para garantir futuras economias. Foi feito um levantamento para alguns dos produtos usados e comparando com as notas fiscais das compras previamente realizadas, viu-se que, devido a nãocomparação de preços a Blim comprou produtos com ágios de até $40 \%$, conforme mostra a Tabela 3: Comparação de preço de detergentes. 
Tabela 3 - Comparação de Preço de Detergentes

\begin{tabular}{|c|c|c|c|c|c|c|c|}
\hline Produto & $\begin{array}{l}\text { Pre } \\
\text { For }\end{array}$ & $\begin{array}{l}\text { ago no } \\
\text { edor } A\end{array}$ & & or $B$ & Fo & dor $C$ & $\begin{array}{c}\text { Média de ágio } \\
\text { pago }\end{array}$ \\
\hline Yellow Pine $5 \mathrm{~L}$ & $R \$$ & 120,00 & $R \$$ & 75,05 & $R \$$ & 98,20 & $39 \%$ \\
\hline Flotador Multiuso & $R \$$ & 58,80 & $R \$$ & 41,96 & $R \$$ & 54,60 & $22 \%$ \\
\hline Vidro Líquido1L & $R \$$ & 750,00 & $R \$$ & 600,00 & $R \$$ & 650,00 & $20 \%$ \\
\hline Peroxy $5 L$ & $R \$$ & 111,90 & $R \$$ & 85,99 & $R \$$ & 83,60 & $32 \%$ \\
\hline
\end{tabular}

Como a Blim sofre com a falta de caixa, é fundamental que todos os processos que tenham algum tipo de custo efetivo sejam revistos, afim de enxugar os custos fixos e variáveis.

Como os sócios não tem um conhecimento aprofundado de como os serviços são realizados e seus custos, muitos dos orçamentos são enviados de forma distorcida, na maioria das vezes com margens altas demais. Isto resulta em orçamentos declinados e uma conversão de cliente bem abaixo do almejado, conforme mostrado anteriormente na Tabela 2. Outra sugestão é que os serviços prestados sejam acompanhados não somente pelo supervisor, mas pelos sócios também. Apenas com uma maior observação sobre como a área operacional funciona e de que forma cada serviço é prestado que os sócios aumentarão seus conhecimentos sobre toda a operação e seus custos. Com o monitoramento dos serviços também poderão ser feitas análises da performance da equipe e de todos seus membros individualmente quanto a $\mathrm{m}^{2} \mathrm{limpo} / \mathrm{h}$, entre outros indicadores de eficiência. Abordando assim dois dos pontos mais importantes citados por Hammer (2010), a otimização de recursos e o controle e quantificação de resultados.

Também foi percebido que os funcionários da empresa não anotam diversas informações consideradas básicas durante algumas das visitas e realização dos serviços, o que acarreta em gargalos durante a comunicação ou envio de informações erradas. Analisando a ficha de prospecção usada pela empresa notou-se a falta de uma análise de risco para serviços onde requer alpinismo e também a falta de informações básicas vitais para a conclusão e aceleração do processo como um todo, informações como: responsável pela vistoria, telefone do solicitante, cargo, se é um serviço considerado 
pós-obra, CNPJ do empreendimento, entre outras. Para que a empresa conseguisse juntar o máximo de informações possíveis sobre seus novos clientes, foi desenvolvida uma nova ficha de prospecção mais completa além de uma ficha de execução de serviço, que deve ser preenchida diariamente com quaisquer ocorrências que aconteçam durante a prestação do serviço. Foi recomendado também que a empresa peça sempre à um colaborador do contratante, responsável por supervisionar o serviço prestado, que assine a ficha de execução, resguardando a Blim de quaisquer responsabilidades, evitando assim futuros passivos e possíveis retrabalhos. Uma comparação das fichas pode ser vista no Anexo II.

Pode-se inferir que o que falta na Blim é exatamente um roteiro detalhado, de todos os processos necessários à realização da venda e da prestação do serviço. Um roteiro organizado de fácil entendimento que todos os colaboradores da equipe possam seguir à risca afim de garantir que os resultados sejam padronizados em todas suas esferas. Somente com a padronização destes procedimentos que a produtividade da empresa irá aumentar, conforme sugerido no capítulo dois, fazendo com que o produto final atende às expectativas dos clientes com uma variação mínima entre os resultados e um menor custo para a empresa.

Apesar da falta do roteiro, ao final do estudo pode-se perceber que o grande desafio da Blim não é em relação a prestação do serviço, mas sim o de alinhamento interno entre as áreas a fim de organizar todos os procedimentos do processo de venda. Quando perguntados, a grande maioria dos clientes se disseram estar muito satisfeitos com os resultados das limpezas, abaixo, nas Figura 6, pode-se ver duas cartas de recomendação feitas por dois de seus clientes para que a Blim fosse incluída na lista de prestadores de serviço dos respectivos grupos. 


\section{Figura 6 - Cartas de Recomendação}

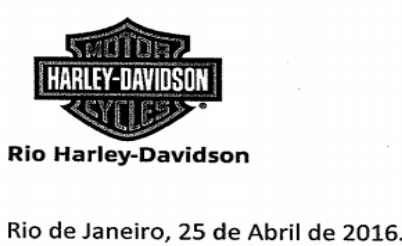

BLIM - Limpeza de Fachadas

Rio de Janeiro - RJ

At. Sr. Sérgio Freire

\begin{abstract}
A Abolição Comércio de Motos Ltda, inscrita sob CNPJ n.o 19.231.827/0001-34, situada à Avenida das Américas, n.o 14.800 - Bairro Recreio dos Bandeirantes - Rio de Janeiro/ RJ - agradece à Blim Limpeza de Fachadas pelos serviços executados durante o período de $4 \mathrm{e}$ 5 de Abril de 2016, de forma rápida, organizada e eficiente, sem que tivéssemos quaisquer prejuízo às nossas rotinas.

Recomendamos a inclusão dessa empresa em nosso cadastro de prestadores de serviços.
\end{abstract}

Cordialmente,

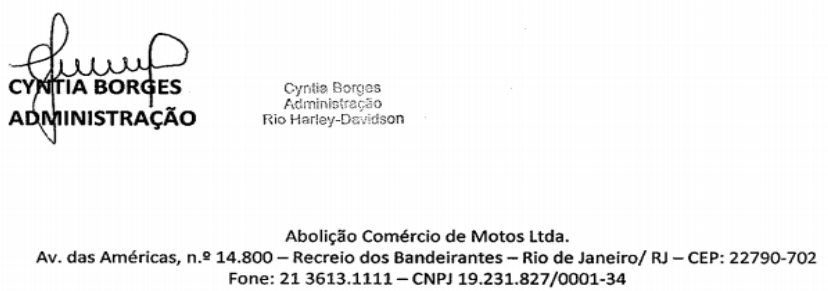

Carta enviada em 23/12/2015

Prezado Sérgio,

Nós da Dinamicar gostaríamos de agradecer à Blim pela prestação do serviço de limpeza dos vidros de nossa loja. 0 serviço foi prestado de forma organizada e conforme combinado entre as partes e, apesar de alguns contratempos durante a execução, a prontidão dos colaboradores da Blim fez com que tudo fosse resolvido de forma rápida e prática. Estamos recomendando a inclusão da empresa no cadastro de fornecedores de toda a rede e esperamos que tenhamos a oportunidade de estarmos trabalhando juntos novamente.

Grande abraço,

Hallam Costa

Sub-Gerente

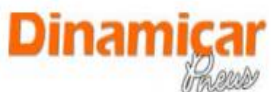

Cabe aos sócios implementar as mudanças necessárias para que todos os POP's do processo de venda sejam realizados; sem exceção. Somente com a criação de uma base de dados sólida e a organização das tarefas internas de cada setor que a empresa começará a crescer de forma orgânica. Não adianta crescer sua base de clientes de forma que os serviços prestados percam qualidade. Não é vantajoso para a empresa se alavancar com dívidas afim de tentar expandir seu portfólio de serviços. A Blim ainda é uma microempresa com uma estrutura enxuta e custos razoavelmente baixos, o que facilita a organização e controle de gastos. Todavia, para que este controle ocorra é necessário que todos estejam esforçados dando seu melhor para que a empresa cresça sempre imputando todos os dados no sistema. 
Todas as sugestões foram feitas com base no referencial teórico de forma a tentar solucionar e melhorar o processo analisado pelo estudo em questão. Através do resultado das entrevistas e de todas as informações colhidas durante o estudo foi feito um novo fluxograma do processo de venda para a empresa de forma em que todos esses novos procedimentos fossem acrescentados. A partir do desenvolvimento deste novo fluxograma espera-se que as melhorias sejam implantadas e que todos os envolvidos consigam visualizar tudo que deve ser feito para melhorar este processo.

Somente quando todas as informações relevantes forem imputadas no sistema que poderão ser confeccionados relatórios gerenciais que de fato reflitam a realidade da microempresa.

\subsection{Sugestões e Recomendações para Novos Estudos}

Segundo pesquisa feita pela Cidade Marketing (2016), empresa especializada em consultorias de marketing, o cliente é a peça mais importante de qualquer empresa, por isso o presente estudo ficou limitado única e exclusivamente ao processo de venda da da Blim. Durante as entrevistas, entretanto, foi detectado que, além da área de vendas, o departamento financeiro também precisa ser analisado mais a fundo, pois falta diversos procedimentos de controle, como o monitoramento de contas a receber, a pagar, de notas fiscais enviadas entre outros. Assim recomenda-se que futuros trabalhos se desenvolvam, com o intuito de otimizar processos financeiros de empresas semelhantes de forma que possam ser aplicados à qualquer microempresa prestadora de serviços, e que os sócios da Blim realizem pesquisas internas após a implementação das sugestões de forma a conseguir comparar os resultados antes $\mathrm{x}$ depois e quantificar as melhorias. 


\section{Referências Bibliográficas}

AALST W.; HOFSTEDE A.; WESKE M. Business Process Management: A Survey. IN: International Conference of Business Process Management (BPM2003), lecture Notes in Computer Science, Springler-Verlag, Berlin, v.2679 p.13-50.

ABPMP BPM CBOK ${ }^{\mathrm{TM}}$. Guide to the Business Process Management Common Body of Knowledge. v.2, p.10-15, 2009 - Disponível em: 〈http://abpmp-br.org> - Acesso entre os dias 10 de fevereiro e 20 de abril de 2017.

BALDMAM, R.; VALLE, R.; PEREIRA, H.; HILST, S.; ABREU, M.; SOBRAL, V. Gerenciamento de Processo de Negócios: BPM - Business Process Management. $2^{a}$ Ed. São Paulo: Ética, 2009.

CAVALCANTI, G.; Setor de Limpeza dá banho na crise e cresce $17 \%$ em cinco anos. Jornal O Globo. 06 setembro 2016. Disponível em: <https://oglobo.globo.com/economia/negocios/setor-de-limpeza-da-banho-na-crisecresce-17-em-cinco-anos-17417114> Acesso em: 09 de abril de 2017

DAVENPORT, T. H. Reengenharia de Processos. Rio de Janeiro: Campus, 1994.

\section{ELO GROUP.; BPM Em Foco - A Evolução do BPM nas Organizações}

Brasileiras. Ano 1 - Edição 1. 2013. Disponível em:

<http://www.sgc.goias.gov.br/upload/arquivos/2014-02/bpm-em-foco---edicao-1.pdf $>$ Acesso em 30 de março de 2017.

GONÇALVES, J. E. L. As empresas são grandes coleções de processos. RAE Revista de Administração de Empresas. São Paulo, v. 40, n.1, Jan./Mar., 2000. 
INAZAWA, R. A aplicação do BPM para Automação de Processos de Negócio nas Organizações. 2009. Trabalho de conclusão de curso (tecnológico) - Faculdade de Tecnologia da Zona Leste, São Paulo.

JESTON, J.; NELIS, J. Business Process Management: practical guidelines to successful implementations, 2006. IN: BALDAM et al. Gerenciamento de processos de negócios. BPM - Business Process Management. $2^{\text {a }}$ Ed. São Paulo: Ética, 2009.

MÜLLER, C. J. Modelo de gestão integrando planejamento estratégico, sitemas de avaliação de desempenho e gerenciamento de processos. 2003 . Tese (Doutorado em Engenharia) - Universidade Federal do Rio Grande do Sul.

N/A.; Geração Flux é uma questão de atitude, não de idade. HSM Educação Executiva. 12 de agosto 2016. Disponível em: <https://www.hsm.com.br/geracaoflux-e-uma-questao-de-atitude-nao-de-idade/> Acesso em 07 de Abril de 2017.

OLIVEIRA, S. Análise e Modelagem de Processos: foco na técnica BPMN. São Paulo: Editora Atlas, 2009. p.50-82.

PAIM, R. Gestão de Processos, pensar, agir e aprender. Porto Alegre: Bookman, 2009.

REIS, K.; A Importância da Comunicação Interna nas Empresas. 30 setembro 2016 Disponível em: <https://www.culturacolaborativa.com/importancia-comunicacaointerna/> Acesso em 11 de abril de 2017.

SMITH, H. \& FINGAR, P. Business Process Management (BPM): The Third Wave, Meghan-Kifer Press: 1st edition, 2007.

WHITE, S. A. Introduction to BPMN. 2004. 


\section{ANEXO I}

Fluxograma criado pela empresa

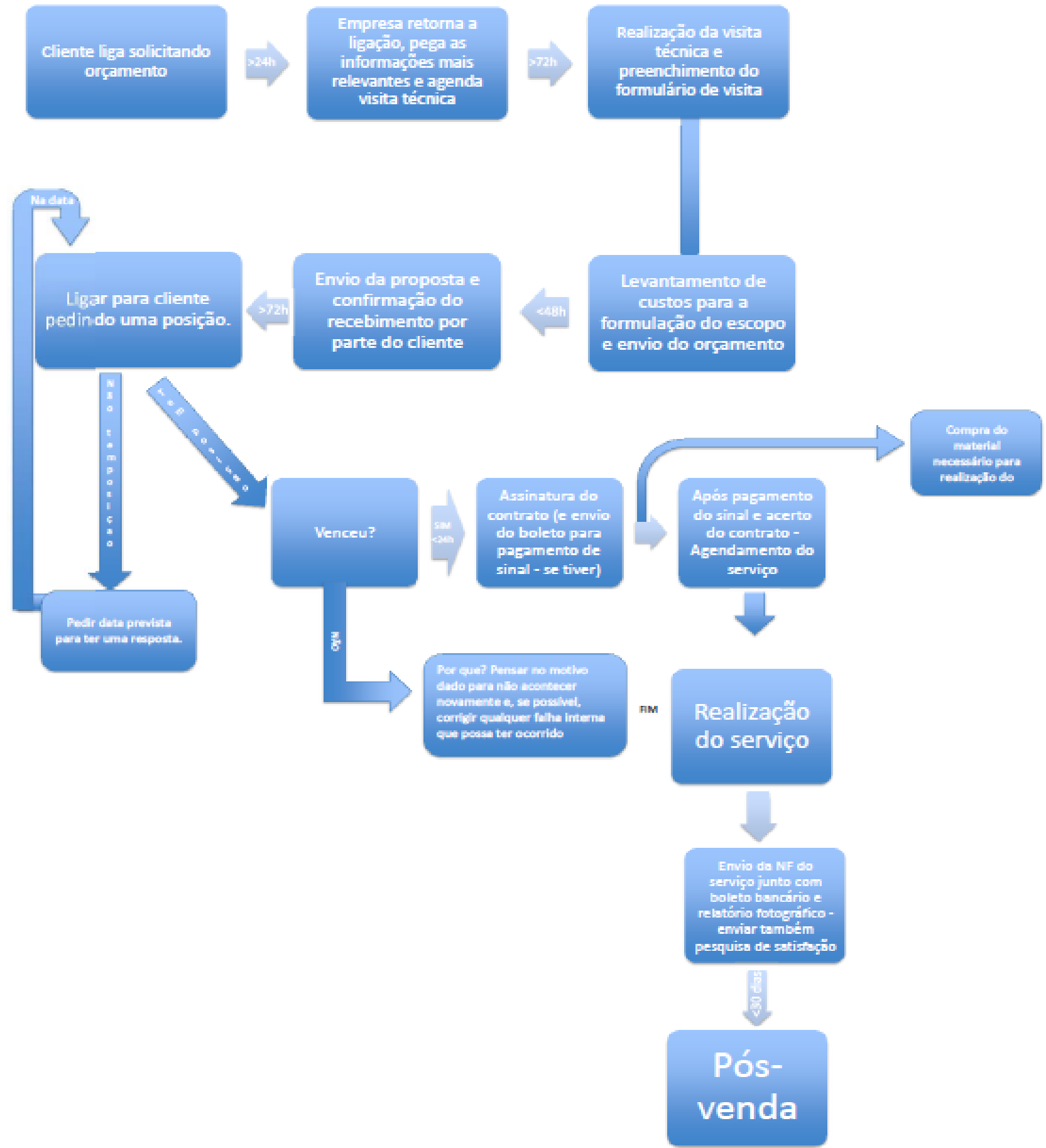




\section{ANEXO II}

Comparação de Fichas de Prospecção:
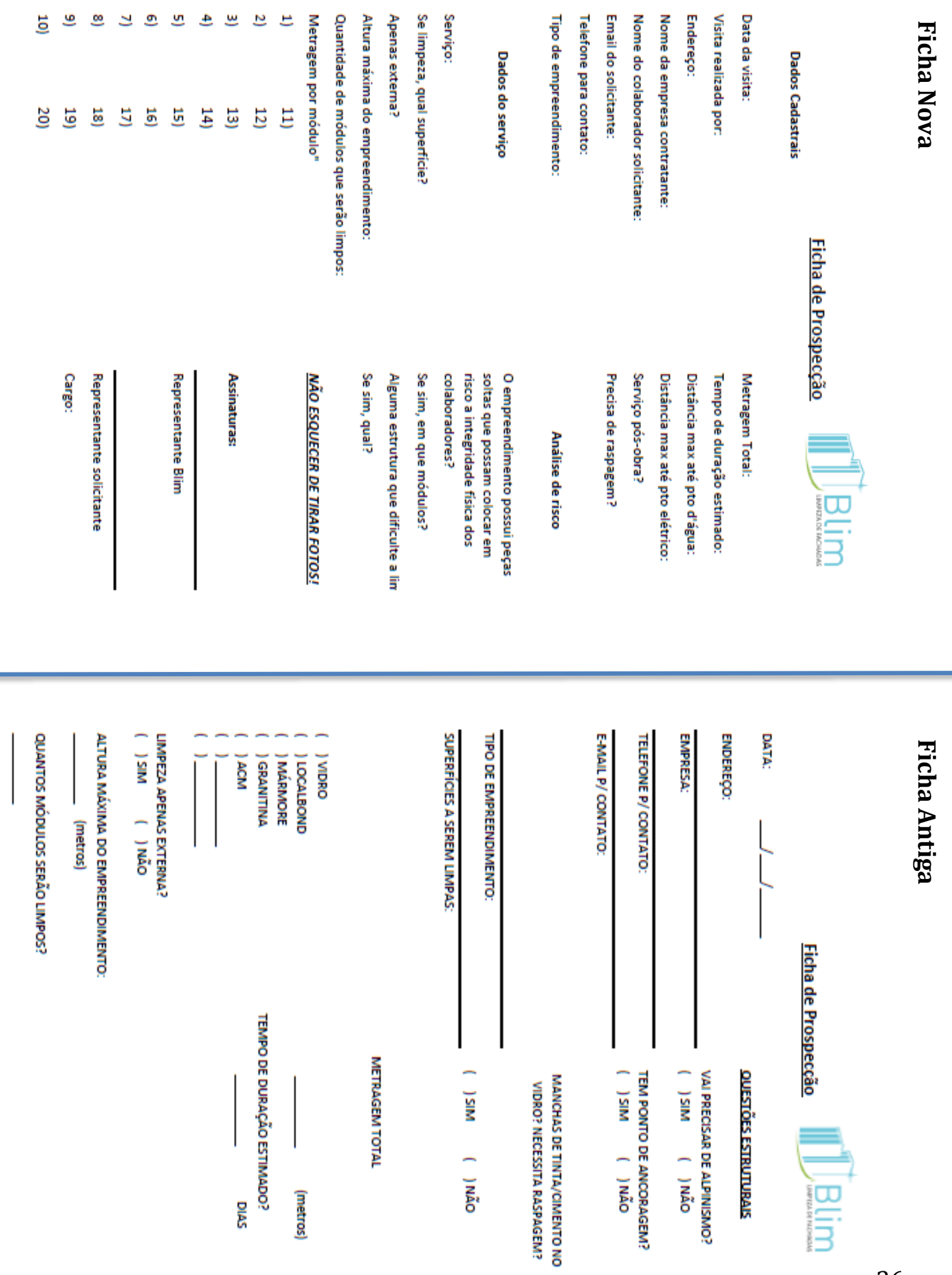

产 